\title{
Türkiye Orman Endüstri Sektörü Altında Faaliyet Gösteren Kağ it, Orman ve Mobilya Firmalarının Finansal Performanslarının Entropi Temelli PROMETHEE Yöntemiyle Analizi
}

\author{
${\text { Rifat } \text { KURT }^{1} \text {, Erol IMMEN*1 }}^{*}$, Selman KARAYILMAZLAR ${ }^{1}$ \\ ${ }^{1}$ Bartın Üniversitesi, Orman Fakültesi, Orman Endüstri Makinaları ve İşletme ABD, 74100, Bartın.
}

Öz

Bu çalıșmada, Türkiye kâğıt ürünleri, orman ürünleri ve mobilya sektörlerinde yer alan on beș ișletmenin finansal performansını belirlemek için Entropi temelli PROMETHEE yöntemiyle bir değerlendirme sistemi oluşturulmuş, değerlendirme göstergelerine göre işletmelerin Borsa İstanbul (BIST) hisselerinin pandemi dönemi ve öncesi mevcut gelişmelere gösterdikleri tepki yansıtılmaya çalışılmıştır. Finansal performans oranlarını kapsayan on bir kriter, 2018-2019 yılları pandemi öncesi ve 2020 yılı pandemi dönemi temel alınarak değerlendirilmiştir. Ağırlıklandırılmış kriterlere göre hisselerin tercih sıralaması oluşturulmuştur. Bu sıralamada ALKA (K1) ve SUMAS (OM4) hissesinin pandemi ve öncesi dönemde en iyi performansı gösterdiği görülmüştür. Genel olarak orman endüstri sektöründe faaliyet gösteren firmaların pandemiden minimum etkilendiği tespit edilmiştir.

Anahtar Kelimeler: Finansal performans, entropi, PROMETHEE, pandemi.

\section{Analysis of Financial Performance of Paper, Forest and Furniture Companies Operating Under The Turkish Forest Industry Sector by Entropy-Based PROMETHEE Method}

\begin{abstract}
In this study, Turkey's paper products, wood products and furniture sectors located to determine the financial performance of the fifteen business Entropy weighted PROMETHEE method with an evaluation system was created, and according to the evaluation indicators, the reaction of the enterprises to the current developments of Borsa Istanbul (BIST) stocks during, and before the pandemic was tried to be reflected. Total eleven criteria covering financial performance ratios were evaluated based on the pre-pandemic period of 2018-2019, and the pandemic period of 2020. According to the weighted criteria, the preference ranking of the stocks has been established. In this ranking, the stock of ALKA (K1) and SUMAS (OM4) showed the best performance in the pandemic and pre-pandemic period. In general, it has been determined that companies operating in the forest industry sector are minimally affected by the pandemic.
\end{abstract}

Keywords: Financial performance, entropy, PROMETHEE, pandemic. 


\section{Giriş}

Ülkemizde ekonomik gelişmelere ve nüfus artışına bağlı olarak yaşam standartlarının da yükselmesiyle birçok üretim sektöründe olduğu gibi orman endüstri sektöründe de son yıllarda önemli kapasite artışları olmuştur (Ylldırım vd., 2016; İstek vd., 2017). Küreselleşme ve rekabetin uluslararası platforma kayması orman ürünleri sektöründe faaliyet gösteren işletmelerin yatırımcılarını, özellikle üretim ve hammaddenin rekabetçi avantajlar sunduğu bölgelere yöneltmiş̧ir (BAKKA, 2012). Ağaç mamulleri ve orman ürünleri imalat sanayi sektörü, iç piyasanın ihtiyacını karşılamanın yanında son yıllardaki gelişmeler doğrultusunda; AB, Rusya, Orta ve Kuzey Afrika, Orta Asya ve Ortadoğu pazarlarna hitap edebilme birikimine sahip olmuştur (TOBB, 2015). Söz konusu sektörün 2020 yllı itibariyle 5,5 milyar dolarlk ihracat seviyesini geçerek 2019 yıll ihracat rakamına ulaştı̆̆ görülmektedir. Türkiye'nin 2020 yllı başındaki \%10'luk ihracat artış hedefi Covid-19 salgının dünya ticaretine negatif etkileri göz önüne alındığında performans olarak kabul edilebilir seviyelerde olduğu belirtilmiştir. Türkiye'nin en çok ihracat yaptığı ülkeler Irak, İsrail, Almanya, Birleşik Krallık, ABD ve Suudi Arabistan olmuştur (Yağc1, 2021).

Finansal performans analizi, bir işletmenin muhasebe ve finansal tablolarından hareketle faaliyet ve finansal yapı özelliklerinin belirlenmesi sürecidir. Böylesine bir analizin amacı, işletmenin finansal kayıt ve raporlarından işletme yönetiminin verimliliğinin ve performansının belirlenmesidir (Bhunia vd., 2011; Meydan vd., 2016). Performans analizleri aynı zamanda hem işletme yöneticilerine işletmenin geleceği ile ilgili önemli kararlar almalarına yardımcı olmakta hem de yatırımcılara ve kredi kurumlarına işletmeyle ilgili bilgi akışı sağlamaktadır. Finansal performansin çeşitli finansal oranlar aracilğ̆ ile ölçülmesi ve değerlendirilmesi mümkün olup performansın ölçümünde göz önünde bulundurulan kriterler araştırmacılara veya yatırımclara göre değişiklik gösterebilir (Soba ve Eren, 2011; Uygurtürk ve Korkmaz, 2012; Metin vd., 2017; Konak vd., 2018). Finansal performansı ölçerken şirketlerin çoklu ve genellikle birbirleri ile uyumsuz kriterleri söz konusu olduğunda, şirketlerin finansal performanslarını ölçebilmek için çok kriterli karar verme yöntemlerinden faydalanılabilmektedir (Ege vd., 2013). Çok kriterli karar verme, çok sayıda kritere göre alternatiflerin avantaj ve dezavantajların değerlendiren analitik yöntemler topluluğudur (Hsieh vd., 2004; Özden vd., 2012). Bu tekniğin temelinde pozitif ideal çözüme en yakın alternatiflerin seçilmesi ve böylece çözümün fayda kriterlerini maksimize ederken maliyet kriterlerini de minimize etmesi yer almaktadır (Özdemir ve Yalçın Seçme, 2009; Uygurtürk ve Korkmaz, 2012).

Çalışmada oran analizleri içinde önemli bir yere sahip olan likidite, karlılık ile faaliyet ve finansal yapı oranlarından baziları kullanılarak Borsa İstanbul'da (BIST) işlem gören orman endüstri sektörüne ait 15 şirketin 2018 ve 2019 yılları ile Covid-19 döneminin başlangıcı olan 2020 yılına ait finansal performanslarının çok kriterli karar verme tekniklerinden biri olan Entropi ağırlkı PROMETHEE yöntemi ile değerlendirilmesi amaçlanmıştır.

\section{Materyal ve Metot}

\subsection{Materyal}

Bu çalışma BIST'te aralıksız faaliyet gösteren kâğıt ürünleri, orman ürünleri ve mobilya sektörlerinde yer alan 15 firmayı kapsamaktadır (Tablo 1). Firmaların finansal performanslarının analizinde 2018, 2019 ve 2020 (Covid 19 dönemi) yıllarındaki finansal oranlardan yararlanılarak, entropiağırlıklı PROMETHEE yöntemi kullanılmıştır. Sektörlere ait finansal oranlar Kamuyu Aydınlatma Platformu (KAP) üzerinden temin edilmiştir (Tablo 2).

Tablo 1. Kâğıtt ürünleri, orman ürünleri ve mobilya sektörlerindeki firmalar ve hisseleri (KAP, 2021).

\begin{tabular}{|c|c|c|}
\hline Sektör & Hisse & Firma \\
\hline Kağıt Ürünleri Sektörü & $\begin{array}{l}\text { ALKA } \\
\text { BAKAB } \\
\text { KAPLM } \\
\text { KARTN } \\
\text { OLMIP } \\
\text { PRZMA } \\
\text { SAMAT } \\
\text { TIRE } \\
\text { VKING }\end{array}$ & $\begin{array}{r}\text { AlkimKağıt San.ve Tic. A.Ş. } \\
\text { Bak Ambalaj San. ve Tic. A.Ş. } \\
\text { Kaplamin Ambalaj San. ve Tic. A.Ş. } \\
\text { Kartonsan Karton San. ve Tic. A.Ş. } \\
\text { Olmuksan International Paper Ambalaj San. ve Tic. A.Ş. } \\
\text { Prizma Pres Matbaacılık Yayıncılı San. ve Tic. A.Ș. } \\
\text { Saray Matbaacılık Kağıtçılık Kırtasiyecilik Tic. ve San. A.Ş. } \\
\text { Mondi Tire Kutsan Kağıt ve Ambalaj San. A.Ş. } \\
\text { Viking Kağıt ve Selüloz A.Ş. }\end{array}$ \\
\hline Orman Ürünleri ve Mobilya Sektörü & $\begin{array}{l}\text { DGKLB } \\
\text { GENTS } \\
\text { ORMA } \\
\text { SUMAS } \\
\text { YATAS } \\
\text { YONGA }\end{array}$ & $\begin{array}{r}\text { Doğtaş Kelebek Mobilya San. ve Tic. A.Ş. } \\
\text { Gentaş DekoratifYüzeyler San. ve Tic. A.Ş. } \\
\text { Orma Orman Mahsulleri İntegre San. ve Tic. A.Ş. } \\
\text { Sumaş Suni Tahta ve Mobilya San. A.Ș. } \\
\text { Yataş Yatak ve Yorgan San. ve Tic. A.Ş. } \\
\text { Yonga Mobilya San. ve Tic. A.Ş. }\end{array}$ \\
\hline
\end{tabular}


Tablo 2. Kullanilan finansal oranlara ait formüller.

\begin{tabular}{|c|c|}
\hline Finansal Oranlar & Formüller \\
\hline \multirow{2}{*}{ Nakit Oran } & Hazır Değerler + Menkul Kıymetler \\
\hline & Kısa Vadeli Yabancı Kaynaklar \\
\hline \multirow{2}{*}{ Cari Oran } & Dönen Varlıklar \\
\hline & Kısa Vadeli Yabancı Kaynaklar \\
\hline \multirow{2}{*}{ Likit Oran } & Dönen Varlıklar - Stoklar \\
\hline & $\overline{\text { Klsa Vadeli Yabancı Kaynaklar }}$ \\
\hline \multirow{2}{*}{ Kısa Vadeli Borçlar / Aktifler Oranı } & Kısa Vadeli Borçlar \\
\hline & Toplam Aktifler \\
\hline \multirow{2}{*}{ Aktiflerin Getirisi (ROI) } & Vergiden Sonraki Net Kar \\
\hline & Toplam Varlıklar \\
\hline \multirow{2}{*}{ B rüt Kar Marjı } & Brüt Satış Karl \\
\hline & Net Satışlar \\
\hline \multirow{2}{*}{ Dönen Varlıklar Devir Hın } & Net Satışlar \\
\hline & Dönen Varlıklar \\
\hline \multirow{2}{*}{ Alacak Devir Hız } & Net Satışlar \\
\hline & Kısa Vadeli Ticari Alacaklar + Uzun vadeli Ticari Alacaklar \\
\hline \multirow{2}{*}{ Aktif (Varlık) Devir Hın } & Net Satış Tutarl \\
\hline & Toplam Aktifler \\
\hline \multirow{2}{*}{ Maddi Duran Varlık Devir Hız } & Net Satışlar \\
\hline & Maddi Duran Varlıklar (Net) \\
\hline \multirow{2}{*}{ Stok Devir Hız } & Satılan Malın Maliyeti \\
\hline & Ortalama Stoklar \\
\hline
\end{tabular}

Finansal performanslanı ölçmek için kağıt sektörü için ALKA (K1), BAKAB (K2), KAPLM (K3), KARTN (K4), OLMIP (K5), PRZMA (K6), SAMAT (K7), TIRE (K8) ve VKING (K9), orman ürünleri ve mobilya sektörü için DGKLB (OM1), GENTS(OM2), ORMA (OM3), SUMAS (OM4), YATAS (OM5) ve YONGA (OM6) his seleri ile hisselerin Dönen Varlıklar Devir Hızı (C1), Kısa Vade Borç / Aktif (C2), Stok Devir Hızı (C3), Aktiflerin Getirisi (C4), Brüt Kar Marjı (C5), Aktif Devir Hızı (C6), Nakit Oran (C7), Cari Oran (C8), Likit Oran (C9), Alacak Devir Hızı (C10) ve Maddi Duran Varlık Devir Hızı (C11) oranları kullanılmıştır (Tablo 3).

Tablo 3. Kâğıt ürünleri, orman ürünleri ve mobilya sektörlerindeki firmaların finansal oranları (KAP, 2021).

\begin{tabular}{|c|c|c|c|c|c|c|c|c|c|c|c|c|c|c|c|}
\hline \multicolumn{16}{|c|}{2020 YILI } \\
\hline & K1 & K2 & $\mathbf{K} \mathbf{3}$ & $\mathbf{K} 4$ & $\mathbf{K 5}$ & K6 & K7 & K8 & K9 & OM1 & OM2 & OM3 & OM4 & OM5 & OM6 \\
\hline $\begin{array}{l}\text { C1 } \\
\text { C2 }\end{array}$ & $\begin{array}{c}1,67 \\
24,95\end{array}$ & $\begin{array}{c}2,02 \\
42,13\end{array}$ & $\begin{array}{l}2,07 \\
67,5\end{array}$ & $\begin{array}{c}2,48 \\
14,56\end{array}$ & $\begin{array}{c}2,05 \\
57,53\end{array}$ & $\begin{array}{c}0,68 \\
22,02\end{array}$ & $\begin{array}{c}1,82 \\
52,36\end{array}$ & $\begin{array}{c}2,23 \\
65,55\end{array}$ & $\begin{array}{c}2,71 \\
87,41\end{array}$ & $\begin{array}{c}1,99 \\
69,79\end{array}$ & $\begin{array}{r}1,56 \\
22,25\end{array}$ & $\begin{array}{c}1,6 \\
50,5\end{array}$ & $\begin{array}{c}1,56 \\
22,06\end{array}$ & $\begin{array}{c}2,51 \\
41,33\end{array}$ & $\begin{array}{c}1,89 \\
41,04\end{array}$ \\
\hline C3 & 5,69 & 4,98 & 6,53 & 5,82 & 6,03 & 1,16 & 2,64 & 7,71 & 5,83 & 2,45 & 2,26 & 4,91 & 4,75 & 3,65 & 2,25 \\
\hline C4 & 149,81 & 118,05 & 127,2 & 144,11 & 139,69 & 29,87 & 111,99 & 137,93 & 84,35 & 111,43 & 107,95 & 48,86 & 123,83 & 148,73 & 101,52 \\
\hline C5 & 25,06 & 18,38 & 21,09 & 22,31 & 17,32 & 12,34 & 18,76 & 17,52 & 22,32 & 32,75 & 30,49 & 25,35 & 24,42 & 39,04 & 25,95 \\
\hline C6 & 1,5 & 1,18 & 1,27 & 1,44 & 1,4 & 0,3 & 1,12 & 1,38 & 0,84 & 1,11 & 1,08 & 0,49 & 1,24 & 1,49 & 1,02 \\
\hline C7 & 151,38 & 37,09 & 2,48 & 181,89 & 2,5 & 0,67 & 0,17 & 1,09 & 7,22 & 2,02 & 44,23 & 0,99 & 233,81 & 50,67 & 40,29 \\
\hline C8 & 3,63 & 1,46 & 0,94 & 4,14 & 1,25 & 1,92 & 1,14 & 0,97 & 0,38 & 0,81 & 3,17 & 0,53 & 3,73 & 1,53 & 1,34 \\
\hline C9 & 2,68 & 0,99 & 0,7 & 2,87 & 0,88 & 0,84 & 0,53 & 0,74 & 0,26 & 0,34 & 1,62 & 0,35 & 2,84 & 0,83 & 0,56 \\
\hline C10 & 4,73 & 4,23 & 3,23 & 10,7 & 3,18 & 1,2 & 4,67 & 3,2 & 5,27 & 6,05 & 6,23 & 3,28 & 24 & 13,42 & 22,14 \\
\hline C11 & 17,08 & 2,96 & 3,28 & 3,85 & 5,92 & 11,68 & 4,32 & 3,57 & 1,23 & 3,17 & 5,70 & 0,65 & 6,72 & 5,14 & 1,90 \\
\hline \multicolumn{16}{|c|}{2019 YILI } \\
\hline & K1 & $\overline{\mathrm{K} 2}$ & $\mathbf{K} \mathbf{3}$ & K4 & $\overline{K 5}$ & K6 & K7 & K8 & K9 & OM1 & OM2 & OM3 & OM4 & OM5 & OM6 \\
\hline C1 & 1,94 & 1,81 & 1,94 & 2,57 & 1,52 & 0,49 & 1,81 & 1,99 & 2,74 & 1,53 & 1,6 & 1,36 & 1,98 & 2,67 & 2,15 \\
\hline C2 & 28,97 & 41,64 & 62,69 & 13,75 & 67,07 & 13,57 & 64,63 & 63,97 & 71,15 & 65,49 & 22,1 & 60,66 & 12,46 & 41,33 & 36,75 \\
\hline $\mathrm{C} 3$ & 6,19 & 4,36 & 7,08 & 4,86 & 4,5 & 0,92 & 2,21 & 8,23 & 5,27 & 1,8 & 2,75 & 4,95 & 4,86 & 3,56 & 2,85 \\
\hline C4 & 168,71 & 101,41 & 117,22 & 142,2 & 114,63 & 21,8 & 120,69 & 125,09 & 81,26 & 85,16 & 103,92 & 49,02 & 149,52 & 141,77 & 105,86 \\
\hline C5 & 17,81 & 15,46 & 17,92 & 16,82 & 10,93 & 29,02 & 5,8 & 14,8 & 18,66 & 30,9 & 18,61 & 22,18 & 26,77 & 41,35 & 17,13 \\
\hline C6 & 1,69 & 1,01 & 1,17 & 1,42 & 1,15 & 0,22 & 1,21 & 1,25 & 0,81 & 0,85 & 1,04 & 0,49 & 1,5 & 1,42 & 1,06 \\
\hline C7 & 147,85 & 22,84 & 1,85 & 119,35 & 1,59 & 4,54 & 0,03 & 2,38 & 2,67 & 0,96 & 52,65 & 1,75 & 379,35 & 24,15 & 10,36 \\
\hline C8 & 3,04 & 1,31 & 0,94 & 4,02 & 0,94 & 3,39 & 0,99 & 0,93 & 0,41 & 0,85 & 3,04 & 0,58 & 6,07 & 1,29 & 1,41 \\
\hline C9 & 2,32 & 0,8 & 0,73 & 2,2 & 0,64 & 2,11 & 0,54 & 0,72 & 0,23 & 0,37 & 1,4 & 0,4 & 4,38 & 0,73 & 0,56 \\
\hline C10 & 3,94 & 3,92 & 2,75 & 10,36 & 2,94 & 0,79 & 8,23 & 2,96 & 5,34 & 4,41 & 5,7 & 2,47 & 23,01 & 8,28 & 10,23 \\
\hline C11 & 15,51 & 2,43 & 2,99 & 3,58 & 4,84 & 5,92 & 7,61 & 3,59 & 1,12 & 2,33 & 5,29 & 0,84 & 5,95 & 3,71 & 2,07 \\
\hline \multicolumn{16}{|c|}{2018 YILI } \\
\hline & K1 & K2 & $\mathbf{K 3}$ & $\mathbf{K} 4$ & K5 & K6 & K7 & K8 & K9 & OM1 & OM2 & OM3 & OM4 & OM5 & OM6 \\
\hline C1 & 2,11 & 1,92 & 2,37 & 2,89 & 1,76 & 0,43 & 1,55 & 2,25 & 3,1 & 1,63 & 1,82 & 1,38 & 2,38 & 2,9 & 2,76 \\
\hline C2 & 28,28 & 43,82 & 59,45 & 13,81 & 65,93 & 8,54 & 52,67 & 67,36 & 62,89 & 73,79 & 21,45 & 59,94 & 17 & 35,67 & 30,58 \\
\hline C3 & 4,79 & 4,03 & 7,01 & 5,79 & 4,69 & 1,15 & 1,42 & 5,99 & 5,58 & 2,03 & 2,57 & 5,46 & 5,06 & 3,33 & 3,23 \\
\hline C4 & 177,97 & 106,94 & 140,12 & 147,57 & 143,23 & 19,54 & 104,26 & 146,48 & 91,61 & 91,18 & 117,36 & 49,81 & 178,18 & 150,63 & 135,08 \\
\hline C5 & 18,79 & 24,45 & 18,4 & 25,19 & 13,95 & 12,29 & 13,48 & 23,26 & 23,1 & 28,91 & 25,33 & 24,32 & 37,34 & 42,41 & 24,14 \\
\hline C6 & 1,78 & 1,07 & 1,4 & 1,48 & 1,43 & 0,2 & 1,04 & 1,46 & 0,92 & 0,91 & 1,17 & 0,5 & 1,78 & 1,51 & 1,35 \\
\hline C7 & 103,24 & 19,38 & 1,73 & 139,4 & 2,03 & 8,14 & 0,1 & 0,93 & 3,7 & 0,76 & 36,53 & 0,25 & 239,71 & 25,24 & 24,43 \\
\hline C8 & 3,03 & 1,31 & 1,04 & 4 & 1,29 & 5,09 & 1,31 & 0,98 & 0,48 & 0,75 & 2,94 & 0,61 & 4,43 & 1,48 & 1,52 \\
\hline C9 & 1,63 & 0,82 & 0,8 & 2,47 & 0,7 & 2,92 & 0,12 & 0,73 & 0,26 & 0,29 & 1,41 & 0,47 & 2,77 & 0,88 & 0,69 \\
\hline C10 & 5,06 & 3,66 & 3,38 & 9,57 & 2,99 & 0,75 & 13,32 & 3,07 & 6,1 & 5,71 & 4,43 & $\begin{array}{l}1,89 \\
1,89\end{array}$ & 123,72 & $\begin{array}{l}9,60 \\
9,92\end{array}$ & $\begin{array}{l}0,97 \\
16,97\end{array}$ \\
\hline C11 & 11,74 & 2,33 & 3,49 & 3,49 & 9,41 & 4,42 & 6,33 & 4,28 & 1,25 & 2,37 & 5,69 & 0,78 & 6,87 & 3,33 & 1,95 \\
\hline
\end{tabular}

Covid-19 salgın öncesi dönem için Tablo 1'de verilen finansal oranlar 2018 ve 2019 yılları bilanço ve kar-zarar tablolarından elde edilmiştir. 2021 yılı itibariyle devam eden Covid-19 salgını sırasındaki finansal oranlar için 2020 yılı bilanço ve kar-zarar tablolarından yararlanılmıştır. Bu oranlar ile sektörlerin şirket hisselerinin Covid19 salgını öncesi ve sonrası karşılaştırmalı finansal performans sıralamaları Entopi temelli PROMETHEE yöntemiyle elde edilmiştir. 


\subsection{Yöntem}

\subsubsection{Entropi}

Shannon (1948) tarafindan enformasyon teorisine uyarlanmış olan Entropi kavramı günümüzde başta fizik bilimi olmak üzere matematik ve mühendislik bilimlerinde yaygın olarak kullanılmaktadır (Wu vd., 2011; Ömürbek vd., 2017; İmren vd., 2021). Olasılık teorisi ile formüle edilmiş olan kavram, bilgi kümeleri arasındaki eşitsizlikleri incelemek için bir ölçüm olarak önerilmiştir. Entropi ağırlık yöntemi, nesnelbir ağırlık yöntemidir. Özellikle, karar vermede iletilen ortalama içsel bilgiyi temsil etmek açısından farklı kriterlerin göreceli yoğunluklarını ölçmede çok uygundur (Shannon, 2001; Zeleny, 2012; Huang vd., 2021). Yöntem genel olarak aşağıdaki aşamalardan oluşur (Wang, 2009; Özdağoğlu vd., 2017; Gumus vd., 2020; Zhao vd., 2020; Ayçin ve Güçlü, 2020; İmren vd., 2021).

Aşama I: Karar matrisinin normalizasyonu; Karar problemlerinde yer alan farklı birimlere sahip kriterlere ilişkin değerler, normalizasyon işlemiyle $[0,1]$ aralığında değer alacak şekilde standart bir hale getirilmelidir. Normalizasyon işlemi Eşitlik (1)'den yararlanılarak gerçekleştirilir.

$$
r_{i j}=\frac{x_{i j}}{\sum_{i=1}^{m} x_{i j}} i=1,2, \ldots . m, \text { ve } j=1,2, \ldots . n
$$

Burada $i$; alternatifi, $j$; kriteri, $m$; karar matrisindeki alternatif sayısını, $n$; karar matrisindeki kriter sayısını, $x_{i j} ; i$. alternatifin $j$. kriterdeki değerini, $r_{i j}$; ise karar matrisindeki normalize edilmiş değerleri göstermektedir.

Aşama II: Kriterlere iliş kin entropi değerlerinin bulunmas1; Her bir değerlendirme kriterinin entropi değerleri $\left(e_{j}\right)$, Eşitlik (2)'te gösterilen şekilde hesaplanır. Burada k değeri, $k=\frac{1}{\ln m}$, sabit bir katsayı olup $0 \leq e_{j} \leq 1$ arasında değer alır.

$$
e_{j}=-k \sum_{i=1}^{m} r_{i j} l n r_{i j}
$$

Aşama III: A ğırlık değerlerinin hesaplanması; Son olarak, her bir kritere ait farklılaşma dereceleri $\left(D_{j}=1-e_{j}\right)$ yardımıyla kriterlerin ağırlıkları $\left(W_{j}\right)$ hesaplanır (Eşitlik 3). Tüm ağırlıkların toplamı 1 olmalıdır.

$$
W_{j}=\frac{1-e_{j}}{\sum_{i=1}^{n}\left(1-e_{i}\right)}
$$

\subsubsection{PROMETHEE}

Tam sıralama için PROMETHEE yöntemi 1982 yılında J. P. Brans tarafindan geliştirilmiştir. Geliştirildiğ $i$ zamandan bu yana çeşitli alanlarda çok kriterleri problemleri çözmek için yaygın olarak kullanılmaktadır. Zamanla karmaşık karar verme durumlarına yardımcı olmak için PROMETHEE yönteminin çeşitli versiyonları da literatüre katılmıştır (Brans ve Mareschal, 2005).

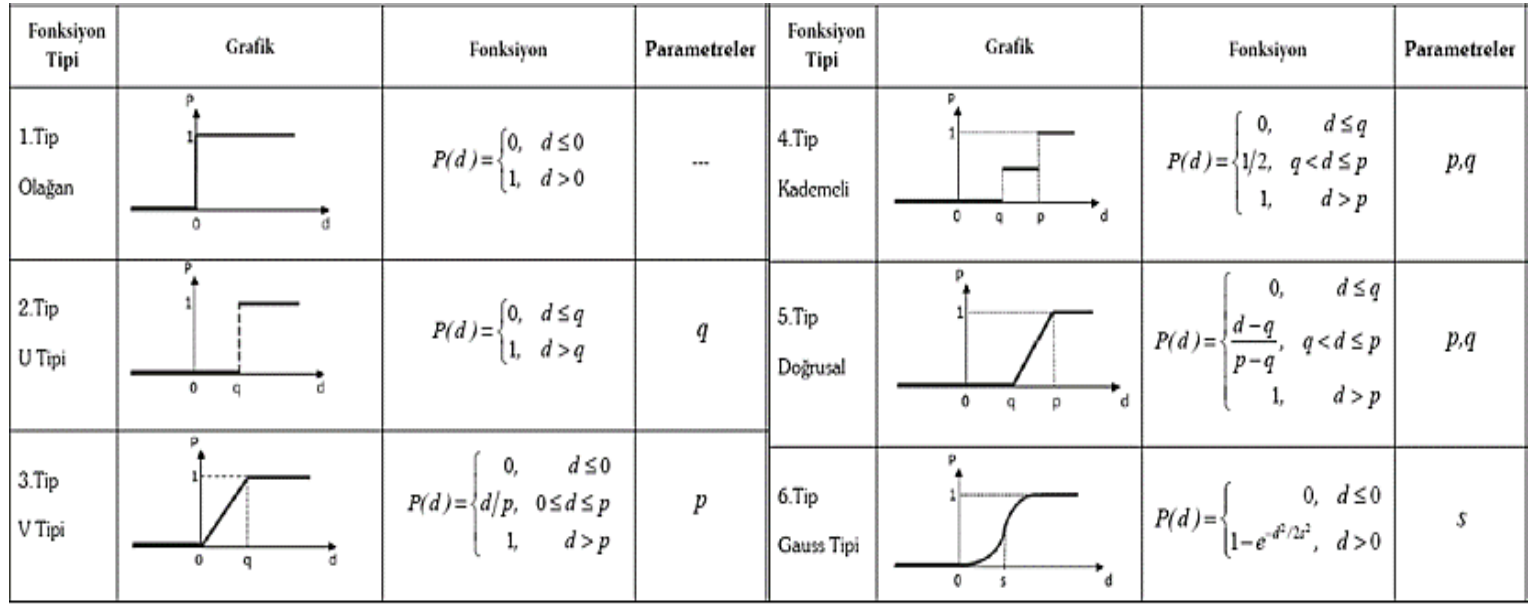

Şekil 1. Genelleştirilmiş kriter türlerine göre tercih fonksiyonları (Geldermann ve Lerche, 2014). 
PROMETHEE, sınırlı bir uygulanabilir alternatifler kümesi üzerinde tam bir sıralama sağlamak için geliştirilmiştir. $\mathrm{Bu}$ yöntemin temel ilkesi, belirlenen her bir kriter boyunca alternatiflerin ikili olarak karşılaştırılmasına dayanır. Her bir kriter için, tercih fonksiyonu, iki alternatif tarafından elde edilen değerlendirmeler arasındaki farkı, sıfırdan bire değişen bir tercih derecesine çevirir (Ignatius vd., 2012). Vincke ve Brans, (1985) tercih fonksiyonunun özelleştirerek seçimini kolaylaştırmak için, altı temel tip önermiştir (Şekil.1) (Albadvi vd., 2007).

Tercih fonksiyonlarında her bir kriter için, bir önemsizlik eşiğinin q değeri, mutlak tercih eşiği p'nin değeri veya p ve q arasında bir ara değer olan s'nin değeri sabittir. PROMETHEE uygulanması için aşamalı prosedür şu şekildedir (Behzadian vd., 2010):

Aşama I: a ve b iki alternatif olmak üzere, her bir kriterdeki alternatiflerin ölçümleri arasındaki sapmaların geniş liği,

$$
\mathrm{d}_{\mathrm{j}}(a, b)=g_{j}(a)-g_{j}(b) \quad j=1, \ldots, k
$$

şeklinde hesaplanır. Yani, $\mathrm{d}_{\mathrm{j}}(a, b)$ ile ikili karşılaştırmalara dayalı sapmalar belirlenir. Bu sapmalar önemsiz olduğunda, baskınlık ilişkisi kuvvetlenmektedir.

Aşama II: Eşitlik (5) kullanılarak tercih fonksiyonu belirlenir.

$$
P_{j}(a, b)=F_{j}\left[d_{j}(a, b)\right] \quad j=1, \ldots, k
$$

Tercih fonksiyonu tersine çevrilerek $\left(-d_{j}(a, b)\right)$ ile belirtilen eşitlik kriterler minimize edilebilir. Burada $P_{j}(a, b)$, bir kriter açısından a ve b gibi iki alternatifin karşılaştırmasından elde edilen olasıllk, $F$ ise $j$. nci kriter için kullanılan $d_{j}(a, b)^{\prime}$ 'nin bir fonksiyonu olarak, her kriterde alternatif $b$ 'ye göre alternatif a'nın tercihini belirtir. Böylece $0 \leq P_{j}(a, b) \leq 1$ dönüşür.

Aşama III: Global bir tercih endeksi hesaplanır.

$$
\pi(a, b)=\sum_{j=1}^{k} P_{j}(a, b) w_{j} \quad \forall a, b \in A
$$

Burada $\pi(a, b)$, tüm kriterler üzerinde a'nın hangi derece ile $b^{\prime}$ ye tercih edildiğini, yani ağırlı̆̆ını $\left(w_{j}\right)$ ifade etmektedir. A kümesi, sonlu bir olası alternatifler kümesidir.

Aşama IV: Alternatiflerin pozitif ve negatif üstünlükdeğerleri hesaplanır.

$$
\begin{aligned}
& \phi^{+}(a)=\frac{1}{n-1} \sum_{x \in A} \pi(a, x) \\
& \phi^{-}(a)=\frac{1}{n-1} \sum_{x \in A} \pi(x, a)
\end{aligned}
$$

Burada $\phi^{+}(a)$, bir alternatif a'nın diğerlerini nasıl geride bıraktığını ifade eder. $\phi^{-}(a)$ ise, bir alternatif a'nın diğerleri tarafindan nasıl geride bırakıldığını ifade etmektedir (Greco vd., 2016).

Aşama V: Tam üstünlük değerinin hesaplanarak, sıralamanın yapılması.

$$
\phi(a)=\phi^{+}(a)-\phi^{-}(a)
$$

\subsection{3. İstatistiki Değerlendirme}

Temel istatistikler (ortalama, standart sapma, minimum ve maksimum değerler, değişim aralıkları), sıralamalar $\left(\phi, \phi^{+}, \phi^{-}\right)$ve uygulamanın çözümünde Visual PROMETHEE paket programı kullanılmıştır. 


\section{Bulgular}

Tablo 4'de kriterlere ilişkin $e_{j}, d_{j}$ ve entropi ağırlıkları $(W)$ eşitlik 1-3 kullanılarak hesaplanmıştır. Söz konusu ağırlıklar firmaların 2018, 2019 ve 2020 yıllarını kapsayan finansal oranlarınına ait ağırlıkların PROMETHEE yöntemiyle performans sıralamanı belirlemede kullanılmıştır. Entropi yardımıyla her yıla ait ağırlıkların ortalaması alınarak her kritere ilişkin ortak bir ağırlık değeri elde edilmiștir.

Tablo 4. Finansal oran kriterlerinin entropi ağrılıkları.

\begin{tabular}{|c|c|c|c|c|c|c|c|c|c|c|}
\hline Kriterler & $e_{\mathbf{j} 2018}$ & $d_{j 2018}$ & $W_{2018}$ & $\mathbf{e}_{\mathrm{j} 2019}$ & $\mathbf{d}_{\mathrm{j} 2019}$ & $W_{2019}$ & $\mathbf{e}_{\mathrm{j} 2020}$ & $\mathrm{~d}_{\mathrm{j} 2020}$ & $W_{2020}$ & $W_{\text {ort }}$ \\
\hline C1 & 0,987281 & 0,012719 & 0,014647 & 0,982057 & 0,017943 & 0,017313 & 0,977183 & 0,022817 & 0,01883 & 0,01693 \\
\hline $\mathrm{C2}$ & 0,959756 & 0,040244 & 0,046344 & 0,952216 & 0,047784 & 0,046107 & 0,949587 & 0,050413 & 0,041603 & 0,044685 \\
\hline C3 & 0,964749 & 0,035251 & 0,040594 & 0,960251 & 0,039749 & 0,038353 & 0,964384 & 0,035616 & 0,029392 & $\mathbf{0 , 0 3 6 1 1 3}$ \\
\hline $\mathrm{C4}$ & 0,979683 & 0,020317 & 0,023396 & 0,974587 & 0,025413 & 0,024521 & 0,97148 & 0,02852 & 0,023536 & 0,023818 \\
\hline C5 & 0,986033 & 0,013967 & 0,016084 & 0,968756 & 0,031244 & 0,030147 & 0,979764 & 0,020236 & 0,0167 & $\mathbf{0 , 0 2 0 9 7 7}$ \\
\hline C6 & 0,979704 & 0,020296 & 0,023372 & 0,974565 & 0,025435 & 0,024542 & 0,971699 & 0,028301 & 0,023356 & $\mathbf{0 , 0 2 3 7 5 7}$ \\
\hline C7 & 0,665692 & 0,334308 & 0,384983 & 0,563119 & 0,436881 & 0,421542 & 0,626269 & 0,373731 & 0,308423 & 0,371649 \\
\hline C8 & 0,922313 & 0,077687 & 0,089463 & 0,897297 & 0,102703 & 0,099097 & 0,913121 & 0,086879 & 0,071697 & 0,086752 \\
\hline C9 & 0,900027 & 0,099973 & 0,115127 & 0,880295 & 0,119705 & 0,115502 & 0,893857 & 0,106143 & 0,087595 & 0,106074 \\
\hline $\mathrm{C} 10$ & 0,88428 & 0,11572 & 0,133261 & 0,898888 & 0,101112 & 0,097562 & 0,615575 & 0,384425 & 0,317248 & 0,18269 \\
\hline C11 & 0,902109 & 0,097891 & 0,11273 & 0,911582 & 0,088418 & 0,085313 & 0,925332 & 0,074668 & 0,06162 & 0,086554 \\
\hline
\end{tabular}

PROMETHEE yöntemi kapsamında finansal oranlardan oluşan kriterlerin tablosu Tablo 1'de verilmiştir. Entropi yöntemi ile her kritere ağırlık atandıktan sonra, çalışmadan elde edilen tüm verilere ait kriterler ve tercih fonksiyonu parametreleri özetlenmiştir (Tablo 5-7). Çalş̧mada, önemsizlik eşiğinin ( $q$ ) koşullu dağılımı ile mutlak tercih eşiği $(p)$ arasındaki farkların kesin bir ölçüsünü sağlayan tercih fonksiyon tipi olarak tip V doğrusal (lineer) fonksiyon kullanılmış ve sonuçları sunulmuştur.

Tablo 5. 2020 yılı (pandemi dönemi) finansal oran kriterlerinin tercih parametreleri ve istatistikleri.

\begin{tabular}{|c|c|c|c|c|}
\hline \multirow{2}{*}{ Kriter } & \multicolumn{2}{|c|}{ Parametre } & \multirow{2}{*}{ Ortalama } & \multirow{2}{*}{ Standart Sapma } \\
\hline & $q$ & $p$ & & \\
\hline C1 (max) & 0,68 & 2,71 & 1,92 & 0,48 \\
\hline C2 (min) & 87,41 & 14,56 & 45,4 & 20,85 \\
\hline C3 (max) & 1,16 & 7,71 & 4,44 & 1,86 \\
\hline $\mathrm{C} 4(\max )$ & 29,87 & 149,81 & 112,35 & 33,94 \\
\hline C5 $(\max )$ & 12,34 & 39,04 & 23,54 & 6,55 \\
\hline C6 (max) & 0,3 & 1,5 & 1,12 & 0,34 \\
\hline C7 (max) & 0,17 & 233,81 & 50,43 & 73,08 \\
\hline C8 $(\max )$ & 0,38 & 4,14 & 1,8 & 1,2 \\
\hline C9 $(\max )$ & 0,26 & 2,87 & 1,14 & 0,89 \\
\hline $\mathbf{C 1 0}(\mathbf{m i n})$ & 24 & 1,2 & 7,7 & 6,73 \\
\hline C11 (max) & 0,65 & 17,08 & 5,14 & 4,1 \\
\hline \multicolumn{5}{|c|}{ PRO METHEE ait n et, pozitif ve negatif öncelikler } \\
\hline Siralama & Hisse & Net Öncelik & Pozitif Öncelik & NegatifÖncelik \\
\hline 1 & ALKA & 0,5545 & 0,6626 & 0,1080 \\
\hline 2 & SUMAS & 0,4301 & 0,6324 & 0,2023 \\
\hline 3 & KARTN & 0,4156 & 0,6198 & 0,2042 \\
\hline 4 & GENTS & 0,2302 & 0,4726 & 0,2424 \\
\hline 5 & YATAS & 0,0656 & 0,3952 & 0,3295 \\
\hline 6 & BAKAB & 0,0647 & 0,3393 & 0,2746 \\
\hline 7 & OLMIP & $-0,0518$ & 0,2649 & 0,3167 \\
\hline 8 & PRZMA & $-0,0696$ & 0,3044 & 0,3740 \\
\hline 9 & KAPLM & $-0,1280$ & 0,2198 & 0,3479 \\
\hline 10 & VKING & $-0,1687$ & 0,2569 & 0,4256 \\
\hline 11 & YONGA & $-0,1704$ & 0,2768 & 0,4472 \\
\hline 12 & TIRE & $-0,1964$ & 0,1672 & 0,3636 \\
\hline 13 & ORMA & $-0,2881$ & 0,1345 & 0,4226 \\
\hline 14 & SAMAT & $-0,3429$ & 0,1060 & 0,4489 \\
\hline 15 & DGKLB & $-0,3448$ & 0,1060 & 0,4508 \\
\hline
\end{tabular}

Tablo 5'de PROMETHEE yöntemiyle 11 kriter eşliğinde belirlenen her hissenin finansal oranlarının tercih parametreleri ve istatistik değerleri verilmiştir. 2020 yılı pandemi döneminde; kriterlere göre en iyi performans gösteren hissenin ALKA $\left(\phi=0,5545, \phi^{+}=0,6626, \phi^{-}=0,1080\right)$ olduğu, en kötü performans gösteren hissenin ise DGKLB $\left(\phi=-0,3448, \phi^{+}=0,1060, \phi^{-}=0,4508\right)$ olduğu görülmektedir. 
Tablo 6. 2019 yılı finansal oran kriterlerinin tercih parametreleri ve is tatistikleri.

\begin{tabular}{|c|c|c|c|c|}
\hline \multirow{2}{*}{ Kriter } & \multicolumn{2}{|c|}{ Parametre } & \multirow{2}{*}{ Ortalama } & \multirow{2}{*}{ Standart Sapma } \\
\hline & $q$ & $\boldsymbol{p}$ & & \\
\hline C1 (max) & 0,49 & 2,74 & 1,87 & 0,55 \\
\hline $\mathrm{C2}(\mathrm{min})$ & 71,15 & 12,46 & 44,42 & 21,27 \\
\hline C3 (max) & 0,92 & 8,23 & 4,29 & 1,93 \\
\hline C4 (max) & 21,80 & 168,71 & 108,55 & 36,98 \\
\hline C5 (max) & 5,80 & 41,35 & 20,28 & 8,44 \\
\hline C6 (max) & 0,22 & 1,69 & 1,09 & 0,37 \\
\hline C7 (max) & 0,03 & 379,35 & 51,49 & 98,07 \\
\hline $\operatorname{C8}(\max )$ & 0,41 & 6,07 & 1,95 & 1,56 \\
\hline C9 (max) & 0,23 & 4,38 & 1,21 & 1,08 \\
\hline C10 (min) & 23,01 & 0,79 & 6,36 & 5,26 \\
\hline C11 (max) & 0,84 & 15,51 & 4,52 & 3,46 \\
\hline \multicolumn{5}{|c|}{ PRO METHEE ait n et, pozitif ve negatif öncelikler } \\
\hline Siralama & Hisse & Net Öncelik & Pozitif Öncelik & NegatifÖncelik \\
\hline 1 & ALKA & 0,6070 & 0,6848 & 0,0778 \\
\hline 2 & SUMAS & 0,4817 & 0,6807 & 0,1990 \\
\hline 3 & PRZMA & 0,2862 & 0,5599 & 0,2737 \\
\hline 4 & GENTS & 0,2788 & 0,5054 & 0,2266 \\
\hline 5 & KARTN & 0,2558 & 0,5176 & 0,2618 \\
\hline 6 & ВАКАВ & 0,1133 & 0,3616 & 0,2483 \\
\hline 7 & YATAS & 0,0041 & 0,3475 & 0,3434 \\
\hline 8 & TIRE & $-0,1375$ & 0,1992 & 0,3367 \\
\hline 9 & KAPLM & $-0,1538$ & 0,1863 & 0,3401 \\
\hline 10 & OLMIP & $-0,1753$ & 0,1693 & 0,3446 \\
\hline 11 & YO NGA & $-0,1866$ & 0,2623 & 0,4489 \\
\hline 12 & O RMA & $-0,2212$ & 0,1697 & 0,3909 \\
\hline 13 & VKING & $-0,3273$ & 0,1331 & 0,4604 \\
\hline 14 & DGKLB & $-0,3651$ & 0,0830 & 0,4481 \\
\hline 15 & SAMAT & $-0,4601$ & 0,1255 & 0,5856 \\
\hline
\end{tabular}

Tablo 6'de pandemi döneminden önceki yıla ait finansal oranlarından oluşan kriterlerin tercih parametreleri verilmiştir. Her bir hisse için finansal oranlar 11 kritere göre temsil edilmektedir. Bu kriterlere göre pandemi döneminde en iyi finansal performans gösteren ALKA hissesi2019 yılında da en iyi performans1 $(\phi=0,6070$, $\left.\phi^{+}=0,6848, \phi^{-}=0,0778\right)$ göstermiştir. Pandemi döneminde ondördüncü sırada olan SAMAT $(\phi=$ $\left.-0,4601, \phi^{+}=0,1255, \phi^{-}=0,5856\right) 2019$ yılında bir alt sirada yer alarak en kötü finansal performans gösteren hiss e olmuştur.

Tablo 7. 2018 y1l finansal oran kriterlerinin tercih parametreleri ve istatistikleri.

\begin{tabular}{|c|c|c|c|c|}
\hline \multirow{2}{*}{ Kriter } & \multicolumn{2}{|c|}{ Parametre } & \multirow{2}{*}{ Ortalama } & \multirow{2}{*}{ Standart Sapma } \\
\hline & $q$ & $p$ & & \\
\hline C1 (max) & 0,43 & 3,37 & 2,15 & 0,75 \\
\hline $\mathrm{C2}$ (min) & 73,79 & 8,54 & 42,72 & 21,14 \\
\hline C3 (max) & 1,15 & 7,01 & 4,14 & 1,72 \\
\hline C4 (max) & 19,54 & 178,18 & 119,99 & 42,73 \\
\hline C5 (max) & 12,29 & 42,41 & 23,69 & 7,97 \\
\hline C6 (max) & 0,20 & 1,78 & 1,20 & 0,43 \\
\hline C7 (max) & 0,10 & 239,71 & 40,37 & 66,40 \\
\hline C8 (max) & 0,48 & 5,09 & 2,02 & 1,44 \\
\hline C9 (max) & 0,12 & 2,92 & 1,13 & 0,88 \\
\hline C10 (min) & 123,72 & 0,75 & 14,04 & 29,63 \\
\hline C11 (max) & 0,78 & 11,74 & 4,52 & 2,95 \\
\hline \multicolumn{5}{|c|}{ PRO METHEE ait net, pozitif ve negatif öncelikler } \\
\hline Siralama & Hisse & Net Öncelik & Pozitif Öncelik & NegatifÖncelik \\
\hline 1 & SUMAS & 0,4387 & 0,6426 & 0,2039 \\
\hline 2 & ALKA & 0,4351 & 0,5829 & 0,1477 \\
\hline 3 & KARTN & 0,4002 & 0,5925 & 0,1923 \\
\hline 4 & GENTS & 0,3349 & 0,5144 & 0,1795 \\
\hline 5 & PRZMA & 0,3071 & 0,5902 & 0,2831 \\
\hline 6 & ВАКАВ & 0,0399 & 0,3466 & 0,3067 \\
\hline 7 & YATAS & $-0,0117$ & 0,3362 & 0,3478 \\
\hline 8 & OLMIP & $-0,0782$ & 0,2667 & 0,3449 \\
\hline 9 & YONGA & $-0,1148$ & 0,2924 & 0,4072 \\
\hline 10 & KAPLM & $-0,1685$ & 0,1995 & 0,3680 \\
\hline 11 & TIRE & $-0,2094$ & 0,1662 & 0,3756 \\
\hline 12 & VKING & $-0,2097$ & 0,2474 & 0,4571 \\
\hline 13 & ORMA & $-0,2795$ & 0,1678 & 0,4474 \\
\hline 14 & DGKLB & $-0,4285$ & 0,0724 & 0,5009 \\
\hline 15 & SAMAT & $-0,4557$ & 0,1085 & 0,5642 \\
\hline
\end{tabular}


Önceki tablolara benzer şekilde, Tablo 7'deki, finansal oranlara göre pandemi döneminde ve 2019 y1lında ikinci sırada yer alan SUMAS hissesi 2018 yılında en iyi finansal performans gösteren hisse olmaktadır $(\phi=0,4387$, $\left.\phi^{+}=0,6426, \phi^{-}=0,2039\right)$. En kötü finansal performans gösteren hissenin ise 2019 y1lında olduğu gibi SAMAT $\left(\phi=-0,4557, \phi^{+}=0,1085, \phi^{-}=0,5642\right)$ olduğu görülmektedir. Şekil 2'de tüm firmalara ait his selerin belirtilen yıllara göre sıralamaları ve değişimi verilmiştir.

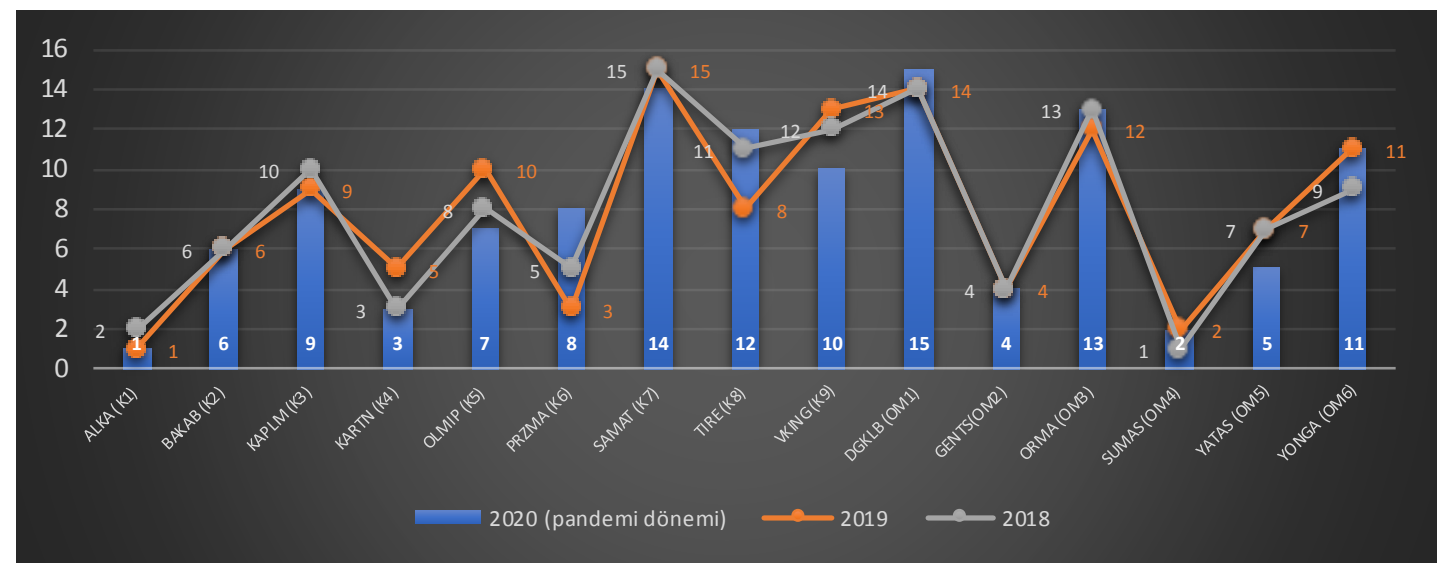

Şekil 2. 2018, 2019 ve 2020 yll finansal oran kriterlerinin tercih parametreleri.

Şekil 2 incelendiğinde 2019 ve 2020 yıllarında ALKA, 2018 yıllarında ise SUMAS ilk sırada yer almaktadır. SAMAT 2018 ve 2019 yıllarında, DGKLB ise 2020 yılında 15 firma içerisinde son surada yeralmıştır. Söz konusu yıllarda en fazla değişim göseren firmalar PRZMA, TIRE, YATAS, KARTN, OLMIP ve VKING olmuştur.

\section{Sonuç ve Öneriler}

Türkiye orman endüstri sektöründe faaliyet gösteren firmaların finansal performanslarını ölçmeyi amaçlayan bu çalışmada aşağıdaki sonuçlar elde edilmiştir.

- Genel olarak belirlenen kriterlere göre firmaların finansal performansının pandemi döneminde önceki iki döneme göre çok fazla etkilenmediği görülmüştür.

- Finansal performanslar açısından değerlendirildiğinde kâğıt sektöründe faaliyet gösteren ALKA ile orman ürünleri ve mobilya sektöründe yer alan SUMAS 2018, 2019 ve 2020 (pandemi dönemi) yıllarında ilk iki sırada yer almıştır.

- Kâğit sektöründe SAMAT ile orman ürünleri ve mobilya sektöründe DGKLB en düşükperformansa sahip his seler olarak belirlenmiştir.

- Kâğıt sektöründe BAKAB, orman ürünleri ve mobilya sektöründe GENTS belirtilen yıllarda finansal performansları bakımından sıralamaları değişmeyen firmalar olmuştur.

- Kâğıt sektöründe faaliyet gösteren PRZMA ve TIRE pandemi döneminde finansal performansı en fazla düşen firma hiss eleri olmuştur.

- Orman ürünleri ve mobilya sektöründe YATAS, kâğıt sektöründe ise KARTN, OLMIP ve VKING pandemi döneminden pozitif etkilenen firma hisseleri olmuştur.

Tüm bu sonuçlar değerlendirildiğinde şirketler arasında büyük ölçekte çok yüksek bir rekabet olmadığ 1 görülmektedir. Bununla birlikte daha güçlü ve daha büyük bir firmaların, mutlaka en iyi sonuçlar elde edeceği kesin değildir. PROMETHEE yaklaşımının, şirketlerin finansal bilgilerini revize etmelerine ve en başarılı şirketlerin finansal durumlarını analiz etmelerine yardımcı olduğu görüşü güçlenmektedir. Gelecek çalışmalarda finansal oran kriterleri değiştirilerek ve farklı çok kriterli karar verme yöntemleri kullanılarak firmaların performans ları detaylı ve karşılaştırmalı olarak analiz edilebilir.

\section{Kaynaklar}

1. Albadvi, A., Chaharsooghi, S. K., Esfahanipour, A. (2007). Decision making in stock trading: An application of PROMETHEE. European journal of operational research, 177(2), 673-683.

2. Ayçin, E, Güçlü, P. (2020). BIST Ticaret Endeksinde Yer Alan İşletmelerin Finansal Performanslarının Entropi ve MAIRCA Yöntemleri ile Değerlendirilmesi. Muhasebe ve Finansman Dergisi, (85), 287-312. 
3. BAKKA, (2012). Batı Karadeniz Kalkınma Ajans1, TR81 Düzey 2 Bölgesi Mobilya ve Orman Ürünleri Sektör Analizi Raporu, 248 s.

4. Behzadian, M., Kazemzadeh, R. B., Albadvi, A., Aghdasi, M. (2010). PROMETHEE: A comprehensive literature review on methodologies and applications. European journal of Operational Research, 200(1), 198-215.

5. Bhunia, A., Mukhuti Sri S., Roy Sri, G. (2011). Financial Performance Analysis-A Case Study. Current Research Journal of Social Sciences 3(3): 269-275.

6. Brans, J., Mareschal, B. (2005). "PROMETHEE methods", Decision in Multicriteria Decision Analysis: State of the Art Surveys (J. Figueira, S. Greco and M. Ehrgott, Eds), (78):163-196.

7. Ege, İlhan, Topaloğlu, E. E., Özyamanoğlu, M. (2013). Finansal performans ile kurumsal yönetim notlari arasindaki ilişki: BIST üzerine bir uygulama. Akademik Araştırmalar ve Çalışmalar Dergisi (AKAD), 5(9), 100-117.

8. Geldermann, J., Lerche, N. (2014). Leitfaden Zur Anwendung Von Methoden Der Multikriteriellen Entscheidungsunterstützung. Georg-Agust Universitaet Göttingen, Lehrstuhl Für Produktion Und Logistik. s. (1-68).

9. Greco, S., Figueira, J., Ehrgott, M. (2016). Multiple criteria decision analysis (Vol. 37). New York: Springer.

10. Gumus, H., Aydemir, D., Altuntas, E, Kurt, R., Imren, E (2020). Cellulose nanofibrils and nanoscaled titanium dioxide-reinforced biopolymer nanocomposites: Selecting the best nanocomposites with multicriteria decision-making methods. Journal of Composite Materials, 54(7), 923-935.

11. Hsieh, T. Y., Lu, S. T., Tzeng, G. H. (2004). Fuzzy MCDM approach for planning and design tenders selection in public office buildings. International journal of project management, 22(7), 573 584., Vol: 22.

12. Huang, W., Zhang, Y., Yu, Y., Xu, Y., Xu, M., Zhang, R., Dieu, G.J., Yin, D. Liu, Z. (2021). Historical data-driven risk assessment of railway dangerous goods transportation system: Comparisons between Entropy Weight Method and Scatter Degree Method. Reliability Engineering \& System Safety, 205, 107236.

13. Ignatius, J., Behzadian, M., Malekan, H. S., Lalitha, D. (2012). Financial performance of Iran's Automotive sector based on PROMETHEE II. In 2012 IEEE International Conference on Management of Innovation \& Technology (ICMIT) (pp. 35-38). IEEE.

14. Imren, E, Kurt, R., Yucedag, C., Bilir, N., Ozel, H. B., Cetin, M., Sevik, H. (2021). Selection of Superior Clones by the Multi-Dimensional Decision-Making Techniques in Scots Pine Seed Orchard. Journal of Forests, 8(1), 13-22.

15. İstek, A., Özlüs oylu, İ., Kızılkaya, A. (2017). Türkiye Ahşap Esaslı Levha Sektör Analizi. Bartın Orman Fakültesi Dergisi, 19 (1), 132-138.

16. KAP, (2021). Kamu aydınlatma platformu, https://www.kap.org.tr/tr/, (Erişim tarihi:15.02.2021).

17. Konak, T., Elbir, G., Yılmaz, S., Karataş, B. M., Durman, Y., Düzakın, H. (2018). Borsa İstanbul'da İşlem Gören Tekstil Firmalarının TOPSIS ve MOORA Yöntemi ile Analizi. Çukurova Üniversitesi İktisadi ve İdari Bilimler Fakültesi Dergisi, 22(1), 11-44.

18. Metin, S., Yaman, S., Korkmaz, T. (2017). Finansal performans in TOPSIS ve MOORA yöntemleri ile belirlenmesi: BİST enerji firmaları üzerine karşılaştırmalı bir uygulama. Kahramanmaraş Sütçü İmam Üniversitesi Sosyal Bilimler Dergisi, 14(2), 371-394.

19. Meydan, C., Yıldırım, B. F., Senger, Ö. (2016). BİST’te işlem gören gıda işletmelerinin finansal performanslarının gri ilişkisel analiz yöntemi kullanılarak değerlendirilmesi. Muhasebe ve Finansman Dergisi, (69), 147-171.

20. Ömürbek, N, Eren, H, Dă̆, O. (2017). ENTROPİ-ARAS ve ENTROPİ-MOOSRA Yöntemleri İle Yaşam Kalitesi Açısından AB Ülkelerinin Değerlendirilmesi. Ömer Halisdemir Üniversitesi İktisadi ve İdari Bilimler Fakültesi Dergisi, 10 (2), 29-48.

21. Özdağoğlu, A., Yakut, E, Bahar, S. (2017). Machine selection in a dairy product company with Entropy and SAW method integration. Dokuz Eylül Üniversitesi İktisadi ve İdari Bilimler Fakültesi Dergisi, 32(1), ss.341-359.

22. Özdemir, A. İ., Yalçın Seçme, N. (2009). İki Aşamalı Stratejik Tedarikçi Seçiminin Bulanık TOPSIS Yöntemi ile Analizi. Afyon Kocatepe Üniversitesi İ.İB.F. Dergisi, 11(2), 79-112.

23. Özden, Ü. H., Başar, Ö. D., Kalkan, S. B. (2012). İMKB'de işlem gören çimento sektöründeki şirketlerin finansal performanslarının vıkor yöntemi ile sıralanması. Ekonometri ve İstatistik eDergisi, (17), 23-44.

24. Shannon, C. E. (1948). A mathematical theory of communication. Bell Syst. Tech. J. 27, 379-423. https://doi.org/10.1002/j.1538-7305.1948.tb01338.x.

25. Shannon, C. E (2001). A mathematical theory of communication. ACM SIGMOBILE mobile computing and communications review, 5(1), 3-55. 
26. Soba, M., Eren, K. (2011). Topsis Yöntemini Kullanarak Finansal ve Finansal Olmayan Oranlara Göre Performans Değerlendirilmesi, Şehirlerarasi Otobüs Sektöründe Bir Uygulama. Sosyal Ekonomik Araştırmalar Dergisi, 11(21), 23-40.

27. TOBB, (2015). Türkiye Odalar ve Borsalar Birliği, Türkiye Orman Ürünleri Meclisi Sektör Raporu, $44 \mathrm{~s}$.

28. Uygurtürk, H., Korkmaz, T. (2012). Finansal Performansın TOPSIS Çok Kriterli Karar Verme Yöntemi ile Belirlenmesi: Ana Metal Sanayi Işletmeleri Üzerine bir Uygulama. Eskişehir Osmangazi Üniversitesi İktisadi ve İdari Bilimler Dergisi, 7(2): 95-115.

29. Vincke, J. P., and Brans, P. (1985). A preference ranking organization method. The PROMETHEE method for MCDM. Management Science, 31(6), 647-656.

30. Wang, Y. J. (2009). Combining grey relation analysis with FMCGDM to evaluate financial performance of Taiwan container lines. Expert Systems with Applications, 36(2), 2424-2432.

31. Wu, J., Sun, J., Liang, L., Zha, Y. (2011). Determination of weights for ultimate cross efficiency using Shannon ENTROPY. Expert Systems With Applications, 38 (5), 5162-5165.

32. Yağcı, C.D. (2021). Ege Mobilya Kâğı ve Orman Ürünleri İhracatçıları Birliği, http://www.eib.org.tr/birlikler-agac-birlik-detay.asp (Erişim tarihi:11.02.2021).

33. Yıldırım, İ., Alevii, C. ve Akyüz, K. C. (2016). Odun Esaslı Levha Sektörünün Dış Ticaret Analizi ve Tahmini. Kastamonu Üniversitesi Orman Fakültesi Dergisi, 16 (2): 370-382.

34. Zeleny, M. (2012). Multiple criteria decision making Kyoto 1975 (Vol. 123). Springer Science \& Business Media.

35. Zhao, D., Li, C., Wang, Q., Yuan, J. (2020). Comprehensive evaluation of national electric power development based on cloud model and entropy method and TOPSIS: A case study in 11 countries. Journal of Cleaner Production, 277, 123190. 